\title{
Time-Dependent Density Functional Theory Study of Structure-Property Relationships in Diarylethene Photochromic Compounds
}

\author{
Pansy D. Patel ${ }^{1,2}$ and Artëm E. Masunov ${ }^{1,2,3}$ \\ ${ }^{1}$ NanoScience Technology Center \\ ${ }^{2}$ Department of Chemistry \\ ${ }^{3}$ Department of Physics, 12424 Research Parkway, Suite 400, University of Central Florida, \\ Orlando, FL 32826 USA \\ amasunov@mail.ucf.edu
}

\begin{abstract}
Photochromic compounds exhibit reversible transition between closed and open isomeric forms upon irradiation accompanied by change in their color. The two isomeric forms differ not only in absorption spectra, but also in various physical and chemical properties and find applications as optical switching and data storage materials. In this contribution we apply Density Functional Theory (DFT) and Time-Dependent DFT (TD-DFT) to predict the equilibrium geometry and absorption spectra of a benchmark set of diarylethene based photochromic compounds in open and closed forms (before and after photocyclization). Comparison of the calculated Bond Length Alternation parameters with those available from the X-ray data indicates M05-2x functional to be the best method for geometry optimization when basis set includes polarization functions. We found M05 functional accurately predicts the maximum absorption wavelength when solvent is taken into account. We recommend combined theory level TD-M05/6-31G*/PCM//M05-2x/6$31 \mathrm{G}^{*} / \mathrm{PCM}$ for prediction of geometrical and spectral parameters of diarylethene derivatives.
\end{abstract}

Keywords: photochromism, density functional theory, electronic spectra, bond length alternation, molecular structure.

\section{Introduction}

Photochromism is light-induced reversible molecular transition between two isomers, closed and open, with different absorption spectra. Apart from the color, the two isomers also differ in various physical and chemical properties such as refractive indices, dielectric constants, oxidation-reduction potentials and geometrical structures. The instant property changes upon photoirradiation can be used in various optoelectronic devices such as optical memory, optical switching, displays and nonlinear optics. Irie and Lehn [1-9] were among the first authors to investigate diarylethenes as a potential candidate for photochromic applications (Fig.1).

In the case of photochromic diarylethenes, the open form has twisted $\pi$-system and is colorless while the closed form with nearly planar $\pi$-system is conjugated and colored. 
Thus, the ground state geometry is essential to predict their characteristic properties. An important geometrical parameter in the conjugated systems is the bond-length alternation (BLA), defined as the difference between the single and double bond lengths. For linear chain oligomers it has been known that the band gap, nonlinear optical (NLO) properties, excited states, etc. are BLA-dependent [10-15].

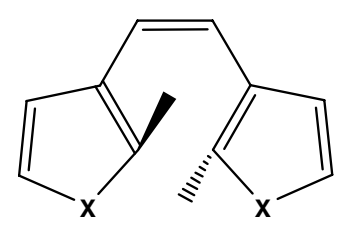

Open form

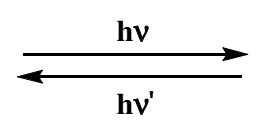

Fig. 1. Photochromic diarylethene compounds $(X=S, O, S e)$

The theoretical predictions of BLA for several series of conjugated oligomers has been conducted by Jacquemin and co-workers [16-23] in the past decade. They performed $a b$ initio calculations on mainly acyclic conjugated systems and concluded that (1) MP2 values are in good agreement with higher-order electron-correlated wavefunction approaches that include triple excitations; (2) basis set effects are relatively limited, and polarized double- $\zeta$ basis is sufficient, at least for DFT calculations; (3) all conventional GGA and meta-GGA provide similar BLA, that are much too small and too rapidly decreasing with the chain lengthens; (4) hybrid functionals correct this trends but to a small extend so that quantitative agreement with MP2 values is still far away; (5) the conformation differences do not alter these three latter conclusions; (6) self-interaction corrections included via the averaged-density self-interaction correction (ADSIC) scheme improves BLA evolution obtained by the conventional DFT approaches. For medium-size oligomers ADSIC predicts BLA in better agreement with MP2, than B3LYP or PBE0. However, diarylethene derivatives had not been investigated in that respect.

In the present contribution we report BLA using different DFT methods to predict the ground state geometry for the open and closed isomers as well as for some by-products. The methods are validated by comparison with the experimental X-ray crystal structures available for some of diarylethene derivatives. Our goal is to establish the computational protocol to investigate structure-property relationships for the diarylethene derivatives aimed to guide the design of new photochromics.

The distinctive absorption spectrum of the two isomeric forms of the photochromic compounds is an essential property of investigation. Experimental absorption spectra $\left(\lambda_{\max }\right)$ of such compounds are determined in different solvents for different derivatives. Recently Jacquemin and co-workers evaluated the $\lambda_{\max }$ for large set of perfluoro derivatives of diarylethenes solvent conditions using Time-Dependent Density Functional (TD-DFT) formalism [24]. However their data is limited for closed isomers only. In the present paper, we have employed TD-DFT formalism to predict the absorption spectra of a benchmark set of photochromic compounds for both open and closed isomeric forms. 


\section{Computational Details}

The calculations have been performed using GAUSSIAN03 package. Different levels of theory were used to find the best method for geometry optimization, followed by absorption spectra predictions. Complete optimizations have been performed on a benchmark set of diarylethene photochromic compounds (Fig.2,a-d) to perform bond length alternation (BLA) analysis and compared to the experimentally determined Xray geometries of a set of structures in order to validate a suitable method as well as basis set for accurate geometry prediction.

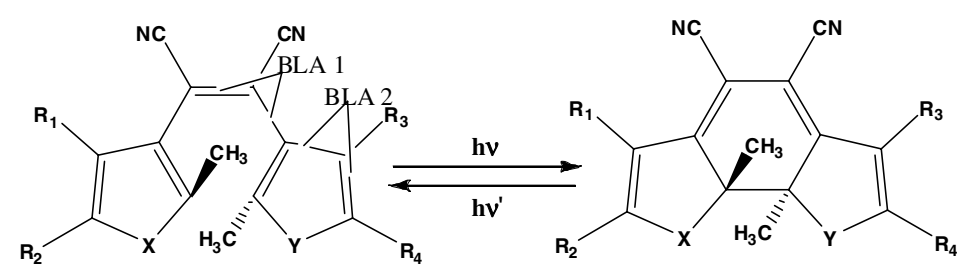

a.

\begin{tabular}{|l|l|l|l|l|l|l|}
\hline Comp & $\mathrm{X}$ & $\mathrm{Y}$ & $\mathrm{R} 1$ & $\mathrm{R} 2$ & $\mathrm{R} 3$ & $\mathrm{R} 4$ \\
\hline DCN-1 & $\mathrm{S}$ & $\mathrm{N}^{-\mathrm{CH}_{3}}$ & $\mathrm{CH}_{3}$ & $\mathrm{CH}_{3}$ & $\mathrm{CH}=\mathrm{CH}-\mathrm{CH}=\mathrm{CH}$ \\
\hline DCN-2 & $\mathrm{N}-\mathrm{CH}_{3}$ & $\mathrm{~N}^{-\mathrm{CH}_{3}}$ & $\mathrm{CH}_{3}$ & $\mathrm{CH}_{3}$ & $\mathrm{CH}=\mathrm{CH}-\mathrm{CH}=\mathrm{CH}$ \\
\hline
\end{tabular}

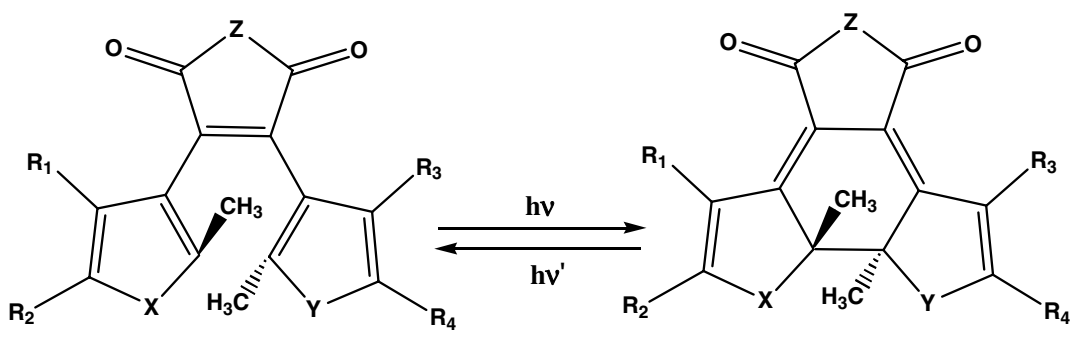

Figure:2b

b.

\begin{tabular}{|l|l|l|l|l|l|l|l|}
\hline Comp & $\mathrm{X}$ & $\mathrm{Y}$ & $\mathrm{Z}$ & $\mathrm{R} 1$ & $\mathrm{R} 2$ & $\mathrm{R} 3$ & $\mathrm{R} 4$ \\
\hline MA-1 & $\mathrm{S}$ & $\mathrm{S}$ & $\mathrm{O}$ & $\mathrm{CH}_{3}$ & $\mathrm{CH}_{3}$ & $\mathrm{CH}_{3}$ & $\mathrm{CH}_{3}$ \\
\hline MA-1-A & $\mathrm{S}$ & $\mathrm{S}$ & $\mathrm{O}$ & \multicolumn{2}{l}{$\mathrm{CH}_{2} \mathrm{CH}-\mathrm{CH}=\mathrm{CH}$} & $\mathrm{CH}=\mathrm{CH}-\mathrm{CH}=\mathrm{CH}$ \\
\hline MA-2 & $\mathrm{S}$ & $\mathrm{N}_{-}-\mathrm{CH}_{3}$ & $\mathrm{O}$ & $\mathrm{CH}_{3}$ & $\mathrm{CH}_{3}$ & $\mathrm{CH}=\mathrm{CH}-\mathrm{CH}=\mathrm{CH}$ \\
\hline MA-2-A & $\mathrm{S}$ & $\mathrm{N}_{-}-\mathrm{CH}_{3}$ & $\mathrm{O}$ & $\mathrm{CH}_{3}$ & $\mathrm{CH}_{3}$ & $\mathrm{CH}=\mathrm{CH}-\mathrm{CH}=\mathrm{CH}$ \\
\hline MA-2-B & $\mathrm{S}$ & $\mathrm{N}_{-}-\mathrm{CH}_{3}$ & $\mathrm{O}$ & $\mathrm{CH}_{3}$ & $\mathrm{CN}$ & $\mathrm{CH}$ & $\mathrm{CH}-\mathrm{CH}=\mathrm{CH}$ \\
\hline MA-3 & $\mathrm{N}-\mathrm{CH}_{3}$ & $\mathrm{~N}-\mathrm{CH}_{3}$ & $\mathrm{O}$ & $\mathrm{CH}=\mathrm{CH}-\mathrm{CH}=\mathrm{CH}$ & $\mathrm{CH}=\mathrm{CH}-\mathrm{CH}=\mathrm{CH}$ \\
\hline MA-hit & $\mathrm{S}$ & $\mathrm{S}$ & $\mathrm{O}$ & $\mathrm{H}$ & $\mathrm{CH}_{3}$ & $\mathrm{H}$ & $\mathrm{CH}_{3}$ \\
\hline Mi & $\mathrm{S}$ & $\mathrm{S}$ & $\mathrm{NH}$ & $\mathrm{CH}_{3}$ & $\mathrm{CH}_{3}$ & $\mathrm{CH}_{3}$ & $\mathrm{CH}_{3}$ \\
\hline
\end{tabular}

Fig. 2(a,b). Benchmark set of open and closed-ring isomers studied in this work (DCNDicyano derivatives, MA-Maleicanhydride derivatives and Mi- Maleimide derivatives) 


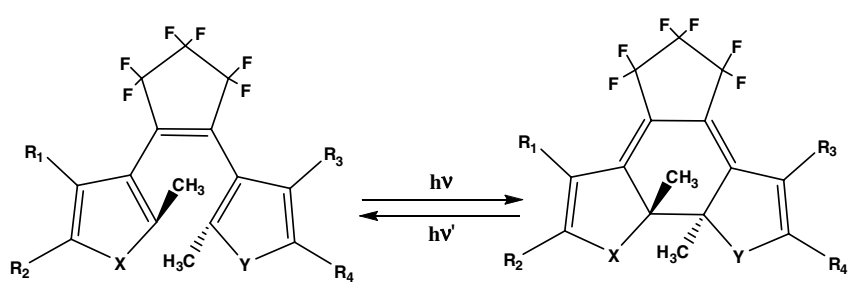

c.

\begin{tabular}{|c|c|c|c|c|c|c|}
\hline Comp & $\mathrm{X}$ & $\mathrm{Y}$ & R1 & $\mathrm{R} 2$ & R3 & $\mathrm{R} 4$ \\
\hline PFC-1-C & S & $\mathrm{S}$ & $\mathrm{CH}_{3}$ & $\mathrm{H}$ & $\mathrm{CH}_{3}$ & $\mathrm{H}$ \\
\hline PFC-1-D & $\mathrm{S}$ & $S$ & $\mathrm{H}$ & $\mathrm{CH}_{3}$ & $\mathrm{H}$ & $\mathrm{CH}_{3}$ \\
\hline PFC-1-E & $S$ & $\mathrm{~S}$ & $\mathrm{CH}_{3}$ & $\mathrm{CH}_{3}$ & $\mathrm{CH}_{3}$ & $\mathrm{CH}_{3}$ \\
\hline PFC-2 & $\mathrm{S}$ & $\mathrm{S}$ & $\mathrm{H}$ & $\mathrm{Ph}$ & $\mathrm{H}$ & $\mathrm{Ph}$ \\
\hline PFC-2-A & $\mathrm{S}$ & $\mathrm{S}$ & $\mathrm{CH}_{3}$ & $\mathrm{Ph}$ & $\mathrm{CH}_{3}$ & $\mathrm{Ph}$ \\
\hline PFC-2-B & $\mathrm{S}$ & $S$ & $\mathrm{CH}_{3}$ & $\mathrm{Ph}-\mathrm{N}-\mathrm{C}_{2} \mathrm{H}_{5}$ & $\mathrm{CH}_{3}$ & $\mathrm{Ph}-\mathrm{N}-\mathrm{C}_{2} \mathrm{H}_{5}$ \\
\hline PFC-3 & $\mathrm{S}$ & $\mathrm{S}$ & $\mathrm{H}$ & Th & $\mathrm{H}$ & Th \\
\hline PFC-4 & $\mathrm{S}$ & $\mathrm{S}$ & $\mathrm{H}$ & $\mathrm{Th}-\mathrm{CH}_{3}$ & $\mathrm{H}$ & Th- $\mathrm{CH}_{3}$ \\
\hline PFC-6 & $S$ & $\mathrm{~N}-\mathrm{CH}_{3}$ & \multicolumn{2}{|c|}{$\mathrm{CH}=\mathrm{CH}-\mathrm{CH}=\mathrm{CH}$} & \multicolumn{2}{|c|}{$\mathrm{CH}=\mathrm{CH}-\mathrm{CH}=\mathrm{CH}$} \\
\hline PFC-6-A & $\mathrm{S}$ & $\mathrm{N}-\mathrm{CH}_{3}$ & $\mathrm{CH}_{3}$ & $\mathrm{CN}$ & \multicolumn{2}{|c|}{$\mathrm{CH}=\mathrm{CH}-\mathrm{CH}=\mathrm{CH}$} \\
\hline PFC-8 & $\mathrm{S}$ & $\mathrm{S}$ & \multicolumn{2}{|c|}{$\mathrm{CH}=\mathrm{CH}-\mathrm{CH}=\mathrm{CH}$} & \multicolumn{2}{|c|}{$\mathrm{CH}=\mathrm{CH}-\mathrm{CH}=\mathrm{CH}$} \\
\hline PFC-B & $\mathrm{O}$ & $\mathrm{O}$ & $\mathrm{CH}_{3}$ & $\mathrm{H}$ & $\mathrm{CH}_{3}$ & $\mathrm{H}$ \\
\hline
\end{tabular}

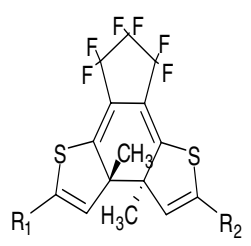

PFC-1: R1, R2=H PFC-1a: R1, $\mathrm{R} 2=\mathrm{CH} 3$

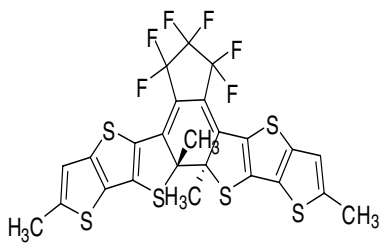

PFC-7

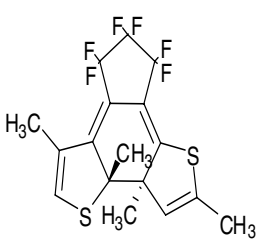

PFC-1b

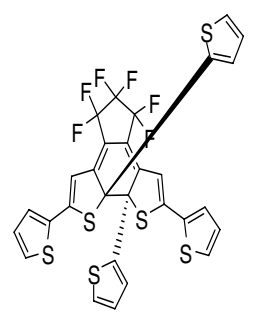

PFC-5

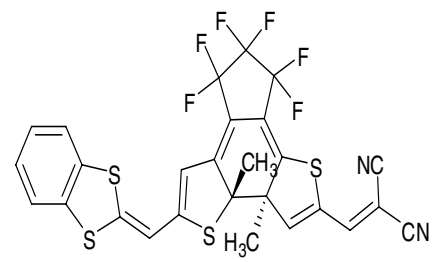

PFC-9

d.

Fig. 2(c,d). (PFC- Perfluorocyclopentene derivatives)

The optimized structures were further used to predict the excitation spectrum of each molecule with Time-Dependent DFT (TD-DFT) formalism. TD-DFT is a quantum mechanical method used to investigate the excited state proprieties of many-body systems. It is important to note that out of several excited states only the one with the maximal oscillator strength was used for comparison with experiment. Often that was 
not the lowest excitation reported by TD-DFT. Several different functionals have been tested to select the best method which can be used to determine the accurate absorption spectra for both isomeric forms of the different derivatives of diarylethenes. Solvent effects were included implicitly by means of non-equilibrium polarizable continuum model (PCM), which uses empirical dielectric constants (both slow orientational and fast electronic components) as well as atomic radii as model parameters. PCM typically provides a good approximation of solvent effects as long as specific interaction with the solvent (such as hydrogen bonds) can be neglected.

The solvents used for the current work were chosen to reproduce the experimental results as close as possible. Heptane (Hep) was used for the compounds whose experimental data was available in hexane while Benzene (Bz), Dicholomethane (DCM) and Acetonitrile (ACN) was used for those compounds whose experimental data was available in the same solvent.

\section{Results and Discussions}

We conduced the geometry optimization at DFT theory level with various exchangecorrelation potentials, including B3LYP, BLYP, BHandHLYP, PBE0, TPSS, BMK,

Table 1. Bond length alternation (BLA, $\AA$ ) and wavelength of the maxima on the absorption spectra $(\lambda \max , \mathrm{nm})$ for a set of diarylethenes calculated at TD-M05/6-31G*/PCM//M052x/6$31 \mathrm{G}^{*} / \mathrm{PCM}$ theory level and compared to the experimental data. See Fig.2a for definition of BLA1 and BLA2.

\begin{tabular}{|c|c|c|c|c|c|c|}
\hline & \multicolumn{3}{|c|}{ Closed isomer } & \multicolumn{3}{|c|}{ Open isomer } \\
\hline & BLA1 & BLA2 & $\lambda_{\max }$ & BLA1 & BLA2 & $\lambda_{\max }$ \\
\hline \multicolumn{7}{|l|}{ PFC-1-d } \\
\hline Experiment $^{\mathrm{a}}$ & 0.095 & 0.091 & 505 & -0.112 & 0.089 & 303 \\
\hline Theory & 0.106 & 0.087 & 505 & -0.113 & 0.080 & 316 \\
\hline \multicolumn{7}{|l|}{ PFC-1-e } \\
\hline Experiment $^{b}$ & & & 529 & -0.132 & 0.095 & \\
\hline Theory & 0.113 & 0.093 & 526 & -0.117 & 0.089 & 279 \\
\hline \multicolumn{7}{|l|}{ PFC-2 } \\
\hline Experiment $^{\mathrm{c}}$ & 0.085 & 0.055 & 575 & -0.112 & 0.050 & 276 \\
\hline Theory & 0.100 & 0.076 & 585 & -0.114 & 0.068 & 287 \\
\hline \multicolumn{7}{|l|}{ PFC-2-et } \\
\hline Experiment $^{\mathrm{d}}$ & 0.089 & 0.059 & 600 & -0.115 & 0.068 & 286 \\
\hline Theory & 0.101 & 0.075 & 611 & -0.116 & 0.067 & 284 \\
\hline \multicolumn{7}{|l|}{ PFC-B } \\
\hline Experiment $^{\mathrm{e}}$ & 0.113 & 0.055 & 469 & -0.120 & 0.053 & 274 \\
\hline Theory & 0.119 & 0.045 & 476 & -0.102 & 0.057 & 251 \\
\hline \multicolumn{7}{|l|}{ PFC-5 } \\
\hline Experiment $^{f}$ & & & 632 & -0.133 & 0.062 & 320 \\
\hline Theory & 0.101 & 0.071 & 611 & -0.116 & 0.060 & 332 \\
\hline \multicolumn{7}{|c|}{ MA-hit-closed } \\
\hline Experiment $^{\mathrm{g}}$ & & & 510 & -0.109 & 0.082 & 403 \\
\hline Theory & 0.091 & 0.077 & 520 & -0.102 & 0.071 & 423 \\
\hline RMSD & 0.006 & 0.007 & 4 & 0.004 & 0.003 & 6 \\
\hline
\end{tabular}

Ref - a-[25], b-[26], c-[27], d-[28],e-[29], f-[30], g-[31] 
Table 2. Maximum absorption wavelengths $\left(\lambda_{\max }, \mathrm{nm}\right)$ measured experimentally and predicted at two theory levels: TD-M05/6-31G*/PCM (T1) andTD-B3LYP/6-31G*/PCM (T2), both use geometry optimized at M052x/6-31G*/PCM level for open and closed isomers of diarylethenes in solution. Deviations of the theoretical values from the experimental ones $\left(\Delta \lambda_{\max }, \mathrm{nm}\right)$ are also reported.

\begin{tabular}{|c|c|c|c|c|c|c|c|c|c|c|}
\hline \multirow[b]{3}{*}{ Molecule } & \multirow[b]{3}{*}{ Solvent } & \multicolumn{4}{|c|}{ Closed } & \multicolumn{5}{|c|}{ Open } \\
\hline & & \multicolumn{2}{|c|}{$\lambda$} & \multicolumn{2}{|l|}{$\Delta \lambda$} & \multicolumn{3}{|c|}{$\lambda$} & \multicolumn{2}{|l|}{$\Delta \lambda$} \\
\hline & & Exp & \begin{tabular}{l|l} 
T1 & T2 \\
\end{tabular} & T1 & T2 & Exp & T1 & T2 & T1 & T2 \\
\hline DCN-1 $^{\text {a }}$ & $\mathrm{Bz}$ & 547 & \begin{tabular}{|l|l|}
552 & 531 \\
\end{tabular} & -5 & 16 & 412 & 457 & 433 & -45 & -21 \\
\hline DCN-2 ${ }^{\mathrm{a}}$ & Bz & 574 & \begin{tabular}{|l|l|}
5533 \\
\end{tabular} & 18 & 41 & 390 & 480 & 377 & -90 & 13 \\
\hline MA-1 ${ }^{b}$ & $\mathbf{B z}$ & 560 & \begin{tabular}{|l|l|l|}
525 & 531 \\
\end{tabular} & 35 & 29 & 335 & 397 & 380 & -62 & -45 \\
\hline МА-1-A ${ }^{c}$ & $\mathbf{B z}$ & 544 & \begin{tabular}{|l|l|}
538 & 531 \\
\end{tabular} & 6 & 13 & 417 & 504 & 475 & -87 & -58 \\
\hline MA-2 ${ }^{\text {a }}$ & Bz & 595 & \begin{tabular}{|l|l|}
563 & 545 \\
\end{tabular} & 32 & 50 & 450 & 507 & 481 & -57 & -31 \\
\hline MA-2-A ${ }^{d}$ & $\mathbf{B z}$ & 680 & \begin{tabular}{l|l|}
683 & 644 \\
\end{tabular} & -3 & 36 & - & 498 & 493 & - & - \\
\hline MA-2-B $^{\text {d }}$ & Bz & 628 & \begin{tabular}{l|l|l|}
62498 \\
\end{tabular} & 4 & 30 & - & 504 & 481 & - & - \\
\hline MA-3 ${ }^{\text {e }}$ & $\mathbf{B z}$ & 620 & \begin{tabular}{l|l|l}
595 & 565 \\
\end{tabular} & 25 & 55 & 470 & 540 & 508 & -70 & -38 \\
\hline $\mathbf{M i}^{\mathbf{f}}$ & Bz & 512 & \begin{tabular}{|l|l|}
496 & 500 \\
\end{tabular} & 16 & 12 & 370 & 391 & 374 & -21 & -4 \\
\hline MA-hit ${ }^{\mathrm{g}}$ & $\mathbf{B z}$ & 510 & \begin{tabular}{|l|l|}
519 & 520 \\
\end{tabular} & -9 & -10 & 403 & 446 & 423 & -43 & -20 \\
\hline PFC-1 $^{\text {h }}$ & Hep & 432 & 428436 & 4 & -4 & 316 & 342 & 332 & -26 & -16 \\
\hline PFC-1-a ${ }^{i}$ & Hep & 425 & \begin{tabular}{|l|l|}
421 & 425 \\
\end{tabular} & 4 & 0 & 336 & 357 & 345 & -21 & -9 \\
\hline PFC-1-b ${ }^{i}$ & Hep & 469 & \begin{tabular}{l|l|l}
462 & 466 \\
\end{tabular} & 7 & 3 & 312 & 311 & 322 & 1 & -10 \\
\hline PFC-1-c ${ }^{j}$ & Hep & 534 & \begin{tabular}{|l|l|}
522 & 528 \\
\end{tabular} & 12 & 6 & 234 & 288 & 280 & -54 & -46 \\
\hline PFC-1-d ${ }^{\mathrm{i}}$ & Hep & 505 & \begin{tabular}{|l|l|}
499 & 505 \\
\end{tabular} & 6 & 0 & 303 & 326 & 316 & -23 & -13 \\
\hline PFC-1-e ${ }^{k}$ & Hep & 529 & \begin{tabular}{l|l|l}
517 & 505 \\
\end{tabular} & 12 & 24 & - & 285 & 266 & - & - \\
\hline PFC-2 ${ }^{1}$ & Hep & 575 & \begin{tabular}{|l|l|}
590 & 585 \\
\end{tabular} & -15 & -10 & 280 & 298 & 287 & -18 & -7 \\
\hline PFC-2-a ${ }^{j}$ & Нер & 562 & \begin{tabular}{|l|l|}
576 & 575 \\
\end{tabular} & -14 & -13 & 262 & 294 & 280 & -32 & -18 \\
\hline PFC-2-b $^{\mathbf{j}}$ & Hep & 597 & \begin{tabular}{|l|l|}
602 & 593 \\
\end{tabular} & -5 & 4 & 305 & 324 & 308 & -19 & -3 \\
\hline PFC-2-et $^{\mathrm{m}}$ & Hep & 600 & \begin{tabular}{|l|l|}
613 & 611 \\
\end{tabular} & -13 & -11 & 286 & 303 & 288 & -17 & -2 \\
\hline PFC-3 $^{\text {n }}$ & $\mathrm{ACN}$ & 605 & \begin{tabular}{|l|l|}
610 & 604 \\
\end{tabular} & -5 & 1 & 312 & 315 & 304 & -3 & 8 \\
\hline PFC-4 $^{\text {n }}$ & $\mathrm{ACN}$ & 612 & \begin{tabular}{|l|l|}
619 & 610 \\
\end{tabular} & -7 & 2 & 320 & 321 & 312 & -1 & 8 \\
\hline${\mathrm{PFC}-5^{\circ}}^{\circ}$ & DCM & 632 & \begin{tabular}{l|l|}
629 & 611 \\
\end{tabular} & 3 & 21 & 320 & 356 & 332 & -36 & -12 \\
\hline PFC-6 $^{\mathrm{p}}$ & $\mathbf{A C N}$ & 565 & \begin{tabular}{l|l|l|}
552 & 534 \\
\end{tabular} & 13 & 31 & 340 & 368 & 356 & -28 & -16 \\
\hline PFC-6-A $^{d}$ & Hep & 665 & \begin{tabular}{|l|l|}
653 & 625 \\
\end{tabular} & 12 & 40 & 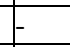 & 375 & 355 & - & - \\
\hline PFC-7 $^{\text {p }}$ & $\mathbf{A C N}$ & 612 & \begin{tabular}{|l|l|}
5965 \\
\end{tabular} & 16 & 27 & 290 & 334 & 327 & -44 & -37 \\
\hline PFC-8 $^{q}$ & Hep & 517 & \begin{tabular}{|l|l|}
523 & 521 \\
\end{tabular} & -6 & -4 & 258 & 269 & 261 & -11 & -3 \\
\hline PFC-9 $^{r}$ & $\mathbf{B z}$ & 828 & \begin{tabular}{|l|l|}
78792 \\
\end{tabular} & 41 & 36 & 354 & 379 & 358 & -25 & -4 \\
\hline $\begin{array}{l}\text { PFC-B }^{\text {s }} \\
\text { RMSD }^{2}\end{array}$ & Hep & 469 & $491 \mid 476$ & $\begin{array}{l}-22 \\
3 \\
\end{array}$ & $\begin{array}{l}-7 \\
4\end{array}$ & 274 & 258 & 251 & 16 & $\begin{array}{l}23 \\
4\end{array}$ \\
\hline
\end{tabular}

Ref: a-[9], b-[8], c-[32], d-[7], e-[33], f-[34], g-[31], h-[35], i-[36], j-[37], k-[26], 1-[27], $\mathrm{m}-[28], \mathrm{n}-[38], \mathrm{o}-[30], \mathrm{p}-[39], \mathrm{q}-[40], \mathrm{r}-[6], \mathrm{s}-[29]$.

M05, and M05-2x. The results of these calculations (which will be published elsewhere) suggest that the M05-2x functional that includes 52\% fraction of the HartreeFock exchange, gives the best agreement with the experimental BLA values. We also compared the maxima on the absorption spectra, evaluated using TD-DFT formalism with the same selection of exchange-correlation potentials using implicit solvent model for both closed and open isomers. We found that M05 method agrees with the experimental $\lambda_{\max }$ values the best. Polarizable continuum model and double- $\zeta$ basis set 
with polarization functions were important to obtain the accurate equilibrium geometry as well as absorption spectra. The comparison of the calculated and experimental BLA parameters and absorption wavelengths for the benchmark subset of diarylethene photochromic compounds is reported in Table 1.

For the rest of the molecules in the benchmark set single crystal X-ray diffraction data were not available. We report their maximum absorption wavelengths at two theory levels: TD-M05/6-31G*/PCM and TD-B3LYP/6-31G*/PCM (with geometry optimized at M052x/6-31G*/PCM level) and compare our predictions with the experimental $\lambda_{\max }$ values in Table 2 . Looking at the RMSD values reported in the last row of that table one can see that B3LYP functional predicts the wavelengths three times closer to experimental values for the closed ring isomers with extended conjugation lengths, than for the open ring isomers. Other functionals, such as BMK, exhibit an opposite trends. The M05 functional seems to be the best compromise, with the average errors of 4-7 $\mathrm{nm}$.

\section{Conclusions}

Several exchange-correlation functionals in combination with TD-DFT formalism were evaluated for predictions of the absorption spectra for both closed and open isomers of diarylethene photochromic compounds. Bond length alternation descriptors were employed to select suitable DFT methods to predict equilibrium geometry in these compounds. We found that a) the most accurate equilibrium geometry based on BLA parameter is best calculated at M05-2x/6-31G*/PCM level; b) TD-DFT spectral data is best reproduced at $\mathrm{M} 05 / 6-31 \mathrm{G} / \mathrm{PCM}$ level with the average deviation form the observed values in the range of 3-7 nm; c) use of polarization functions in the basis set is important to obtain the best geometry; d) solvent effects as described by polarizable continuum model (PCM) are important for the accurate predictions of the spectral data with TDDFT. We recommend theory level TD-M05/6-31G*/PCM//M052x/6-31G*/PCM for prediction of geometrical and spectral parameters (BLA and the $\lambda_{\max }$ values) for both closed and open isomers of diarylethene derivatives. This opens a possibility to establish structure-property relationship for diarylethene photochromics to assist in rational design of improved materials for photoswitching and data storage applications.

\section{Acknowledgements}

This work was supported in part by the National Science Foundation Grant No. CCF 0740344. The authors are thankful to DOE NERSC, UCF I2Lab, and UCF Institute for Simulations and Training (IST) HPC Stokes facility for the generous donation of the computer time.

\section{References}

1. Nakamura, S., Yokojima, S., Uchida, K., Tsujioka, T., Goldberg, A., Murakami, A., Shinoda, K., Mikami, M., Kobayashi, T., Kobatake, S., Matsuda, K., Irie, M.: Theoretical investigation on photochromic diarylethene: A short review. J. Photochem. Photobiol. AChem. 200, 10-18 (2008) 
2. Yamaguchi, T., Takami, S., Irie, M.: Photochromic properties of 1,2-bis (6-substitute-2methyl-1-benzofuran-3-yl) ethene derivatives. J. Photochem. Photobiol. A-Chem. 193, 146-152 (2008)

3. Yamaguchi, T., Uchida, K., Irie, M.: Photochromic properties of diarylethene derivatives having benzofuran and benzothiophene rings based on regioisomers. Bull. Chem. Soc. Jpn. 81, 644-652 (2008)

4. Gilat, S.L., Kawai, S.H., Lehn, J.M.: Light-Triggered Electrical and Optical Switching Devices. J. Chem. Soc.-Chem. Commun., 1439-1442 (1993)

5. Gilat, S.L., Kawai, S.H., Lehn, J.M.: Light-Triggered Electrical and Optical Switching Devices. Molecular Crystals and Liquid Crystals Science and Technology Section aMolecular Crystals and Liquid Crystals 246, 323-326 (1994)

6. Gilat, S.L., Kawai, S.H., Lehn, J.M.: Light-Triggered Molecular Devices - Photochemical Switching of Optical and Electrochemical Properties in Molecular Wire Type Diarylethene Species. Chem.-Eur. J. 1, 275-284 (1995)

7. Irie, M.: Photochromism: Memories and switches - Introduction. Chemical Reviews 100, $1683(2000)$

8. Irie, M., Mohri, M.: Thermally Irreversible Photochromic Systems - Reversible Photocyclization of Diarylethene Derivatives. J. Org. Chem. 53, 803-808 (1988)

9. Nakayama, Y., Hayashi, K., Irie, M.: Thermally Irreversible Phtotchromic Systems - Reversible Photocyclization of Nonsymmetrical Diarylethene Derivatives Bull. Chem. Soc. Jpn. 64, 789-795 (1991)

10. Bartkowiak, W., Zalesny, R., Leszczynski, J.: Relation between bond-length alternation and two-photon absorption of a push-pull conjugated molecules: a quantum-chemical study. Chem. Phys. 287, 103-112 (2003)

11. BlanchardDesce, M., Alain, V., Bedworth, P.V., Marder, S.R., Fort, A., Runser, C., Barzoukas, M., Lebus, S., Wortmann, R.: Large quadratic hyperpolarizabilities with donoracceptor polyenes exhibiting optimum bond length alternation: Correlation between structure and hyperpolarizability. Chem.-Eur. J. 3, 1091-1104 (1997)

12. Bourhill, G., Bredas, J.L., Cheng, L.T., Marder, S.R., Meyers, F., Perry, J.W., Tiemann, B.G.: Experimental Demonstration of the Dependence of the 1st Hyperpolarizability of Donor-Acceptor-Substituted Polyenes on the Ground-State Polarization and Bond-Length Alternation. J. Am. Chem. Soc. 116, 2619-2620 (1994)

13. Choi, C.H., Kertesz, M., Karpfen, A.: The effects of electron correlation on the degree of bond alternation and electronic structure of oligomers of polyacetylene. J. Chem. Phys. 107, 6712-6721 (1997)

14. Kirtman, B., Champagne, B., Bishop, D.M.: Electric field simulation of substituents in donor-acceptor polyenes: A comparison with ab initio predictions for dipole moments, polarizabilities, and hyperpolarizabilities. J. Am. Chem. Soc. 122, 8007-8012 (2000)

15. Meyers, F., Marder, S.R., Pierce, B.M., Bredas, J.L.: Electric-Field Modulated NonlinearOptical Properties of Donor-Acceptor Polyenes - Sum-Over-States Investigation of the Relationship Between Molecular Polarizabilities (Alpha, Beta, and Gamma) and BondLength Alternation. J. Am. Chem. Soc. 116, 10703-10714 (1994)

16. Jacquemin, D., Femenias, A., Chermette, H., Ciofini, I., Adamo, C., Andre, J.M., Perpete, E.A.: Assessment of several hybrid DFT functionals for the evaluation of bond length alternation of increasingly long oligomers. J. Phys. Chem. A 110, 5952-5959 (2006)

17. Jacquemin, D., Perpete, E.A.: Ab initio calculations of the colour of closed-ring diarylethenes: TD-DFT estimates for molecular switches. Chem. Phys. Lett. 429, 147-152 (2006) 
18. Jacquemin, D., Perpete, E.A., Chermette, H., Ciofini, I., Adamo, C.: Comparison of theoretical approaches for computing the bond length alternation of polymethineimine. Chem. Phys. 332, 79-85 (2007)

19. Jacquemin, D., Perpete, E.A., Ciofini, I., Adamo, C.: Assessment of recently for the evaluation of the developed density functional approaches bond length alternation in polyacetylene. Chem. Phys. Lett. 405, 376-381 (2005)

20. Perpete, E.A., Jacquemin, D.: An ab initio scheme for quantitative predictions of the visible spectra of diarylethenes. J. Photochem. Photobiol. A-Chem. 187, 40-44 (2007)

21. Perpete, E.A., Maurel, F., Jacquemin, D.: TD-DFT investigation of diarylethene dyes with cyclopentene, dihydrothiophene, and dihydropyrrole bridges. J. Phys. Chem. A 111, 55285535 (2007)

22. Perrier, A., Maurel, F., Aubard, J.: Theoretical study of the electronic and optical properties of photochromic dithienylethene derivatives connected to small gold clusters. J. Phys. Chem. A 111, 9688-9698 (2007)

23. Perrier, A., Maurel, F., Aubard, J.: Theoretical investigation of the substituent effect on the electronic and optical properties of photochromic dithienylethene derivatives. J. Photochem. Photobiol. A-Chem. 189, 167-176 (2007)

24. Maurel, F., Perrier, A., Perpete, E.A., Jacquemin, D.: A theoretical study of the perfluorodiarylethenes electronic spectra. J. Photochem. Photobiol. A-Chem. 199, 211-223 (2008)

25. Kobatake, S., Yamada, T., Uchida, K., Kato, N., Irie, M.: Photochromism of 1,2-bis(2,5dimethyl-3-thienyl)perfluorocyclopentene in a single crystalline phase. J. Am. Chem. Soc. 121, 2380-2386 (1999)

26. Yamada, T., Kobatake, S., Irie, M.: Single-crystalline photochromism of diarylethene mixtures. Bull. Chem. Soc. Jpn. 75, 167-173 (2002)

27. Irie, M., Lifka, T., Kobatake, S., Kato, N.: Photochromism of 1,2-bis(2-methyl-5-phenyl-3thienyl)perfluorocyclopentene in a single-crystalline phase. J. Am. Chem. Soc. 122, 48714876 (2000)

28. Kobatake, S., Shibata, K., Uchida, K., Irie, M.: Photochromism of 1,2-bis(2-ethyl-5phenyl-3-thienyl)perfluorocyclopentene in a single-crystalline phase. Conrotatory thermal cycloreversion of the closed-ring isomer. J. Am. Chem. Soc. 122, 12135-12141 (2000)

29. Yamaguchi, T., Irie, M.: Photochromism of bis(2-alkyl-1-benzofuran-3yl)perfluorocyclopentene derivatives. J. Org. Chem. 70, 10323-10328 (2005)

30. Peters, A., McDonald, R., Branda, N.R.: Regulating pi-conjugated pathways using a photochromic 1,2-dithienylcyclopentene. Chem. Commun., 2274-2275 (2002)

31. Shirinyan, V.Z., Krayshkin, M.M., Belenkii, L.I.: Photochromic dihetarylethenes. 8. A new approach to the synthesis of 3, 4-bis (2, 5-dimethyl-3-thienyl)furan-2, 5-dione as potential photochrome, 81 (January 2001); Khim. Geterotsiklicheskikh Soedin., 426 (2001)

32. Uchida, K., Nakayama, Y., Irie, M.: Thermally Irreversible Photochromic Systems - Reversible Photocyclization of 1,2-Bis(benzo[b]thiophen-3-yl)ethene Derivatives. Bull. Chem. Soc. Jpn. 63, 1311-1315 (1990)

33. Nakayama, Y., Hayashi, K., Irie, M.: Thermally Irreversible Photochromic Systems - Reversible Photocyclization of 1,2-Diselenenylethene and 1,2-Diindolylethene Derivatives. J. Org. Chem. 55, 2592-2596 (1990)

34. Uchida, K., Kido, Y., Yamaguchi, T., Irie, M.: Thermally irreversible photochromic systems. Reversible photocyclization of 2-(1-benzothiophen-3-yl)-3-(2 or 3thienyl)maleimide derivatives. Bull. Chem. Soc. Jpn. 71, 1101-1108 (1998)

35. Fukaminato, T., Kawai, T., Kobatake, S., Irie, M.: Fluorescence of photochromic 1,2bis(3-methyl-2-thienyl)ethene. J. Phys. Chem. B 107, 8372-8377 (2003) 
36. Irie, M., Uchida, K., Eriguchi, T., Tsuzuki, H.: Photochromism of Single-Crystalline Diarylethenes. Chem. Lett., 899-900 (1995)

37. Irie, M., Sakemura, K., Okinaka, M., Uchida, K.: Photochromism of dithienylethenes with electron-donating substituents. J. Org. Chem. 60, 8305-8309 (1995)

38. Peters, A., Branda, N.R.: Electrochemically induced ring-closing of photochromic 1,2dithienylcyclopentenes. Chem. Commun., 954-955 (2003)

39. Moriyama, Y., Matsuda, K., Tanifuji, N., Irie, S., Irie, M.: Electrochemical cyclization/cycloreversion reactions of diarylethenes. Org. Lett. 7, 3315-3318 (2005)

40. Hanazawa, M., Sumiya, R., Horikawa, Y., Irie, M.: Thermally Irreversible Photochromic Systems - Reversible Photocyclization of 1,2-Bis(2-methylbenzo[b]thiophen-3yl)Perfluorocycloalkene Derivatives. J. Chem. Soc.-Chem. Commun., 206-207 (1992) 